\title{
Improvement on Translation Talents Development Mode from the Perspective of Market Orientation
}

\author{
Yanlin Guo \\ Xi'an Fanyi University, Xi'an, Shaanxi, China.
}

How to cite this paper: Yanlin Guo (2021). Improvement on Translation Talents Development Mode from the Perspective of Market Orientation. The Educational Review, USA, 5(8), 245-256.

DOI: $10.26855 /$ er.2021.08.001

Received: July 7, 2021

Accepted: July 30, 2021

Published: August 12, 2021

Corresponding author: Yanlin Guo, Xi'an Fanyi University University, Xi'an, Shaanxi, China.

Email: 2057919516@qq.com

\begin{abstract}
Tasks and activities undertaken by translators are constantly enriched and changed due to the emergence and development of language service industries, and on the other hand, the development of these industries closely relies on the technical improvement and qualified personnel. However, as an essential supplier, the universities find it hard to cater to the industrial trend and are in urgent need to reconsider the development mode of cultivating the translation talents. The language services, with a continually development and constantly growing standardization, plays a central role to provide first-hand information and reference for universities to take more effective and qualified talents development mode, and brings the collaborative cultivation into full play. Based on analysis of current status of the industry and the translation teaching status, the study is designed to explore a feasible and applicable translation talents teaching mode, from aspects of building the cooperative mechanism between industry and university, improving the curriculum system, implementing project-based teaching mode, and reconstructing the assessment system, respectively.
\end{abstract}

\section{Keywords}

Language Service, Talent Development Mode, Cooperation of Industry \& University, Market Orientation

From very earlier time, many translation scholars have turned their eyes to the relationship between translation education and market demand (Durban et al., 2003; Li et al., 2001; Li et al., 2003), and made an attempt to try to improve the quality of the talents cultivation through the joint efforts of the universities and industries. Agreements have been reached that translation education cannot and should not be completely beyond touch of markets, and market demands should be a crucial factor included in the curriculum design. It is no doubt that the curriculum system considering market demand factors will accelerate the transformation of translation graduates from students to professional language service practitioners. However, the question is how to proceed the talents development mode to a higher and more systematic level.

\section{Analysis on the Development of Language Services and the Demands for Translation Teaching}

\subsection{Development Status of Language Services}

Translation services, subordinate to the language service industries, such as professional document translation, conference translation, multimedia translation, editing and typesetting, multilingual technical writing, website and software localization, and language service outsourcing, have gradually emerged into the business scope of translation enterprises. The standards for translation project management, translation customer service, and translation quality monitoring 
are also getting higher, equipped with obvious service industry characteristics and increasingly clearer professional requirements.

As a profession, translation has gone through quite a long time in China. Its formation can be traced back to the Zhou Dynasty, and it has been maturing in the period of translating and disseminating Buddhist scriptures. However, the integration of translation into the language service industry has only gone through a decade and still lies in the initial stage. As an emerging industry, language service industry plays an increasingly important role in the development of national economy and culture, and gradually draws the attention of the academic world. Since the first National Symposium on Translation Theory held in 1987, there has been a discussion on the nature and status of translation studies: "translation studies, as a science researching on the translation, should or not set as an independent disciplinary". In 2010, Translation Association of China held the first International Conference on Language Service Industry in Beijing, on which defined the broad scope of language service, and made it clear that language service industry includes all institutions engaged in multilingual conversion and related supporting services (Report on China' Translation Industry, 2014). Yao Yazhi and Si Xianzhu put forward that enterprises should be introduced to the university as the "second classroom” for students (Yao Yazhi, 2018).

CSA research, the world's top language service consulting company, released the top 100 language service enterprises around the world and the top language service enterprises in eight regions on July $6^{\text {th }}$, 2021. Among them, the operating revenue of the top 100 global language service enterprises in 2020 was up to $\$ 8.11$ billion, an increase of $4.1 \%$ over \$7.79 billion in 2019; there are 30 enterprises in Asia-Pacific area on the list, among which 13 enterprises in China are listed on the top 30 language service industries in Asia-Pacific area. Among them, there are 10 mainland enterprises, including wensihaihui, Shunyu global Link (Shunyu huanqiutong), Sichuan Language Bridge (Sichuan Yuyan Qiao), Shenzhen Xinyu wisdom (Shenzhen Xinyu Zhihui), angel translation (Tianshi Fanyi), Xiamen Jingyida Translation, Haoboyi Translation, Beijing Yue'er, Beijing Sibirui Translation, Shanghai Tangneng; two Taiwan enterprises, including: Tongyi translation and Chuangling; and one in Hong Kong, that is DataSource (csa-research).

From the year of 2015 to 2019, China's language service industry gained very rapid development and its output value has grown steadily. The professional fields involved in translation business are gradually converting from chemical manufacturing to science and technology education.

The COVID-19 poses a great impact on the language service and the employment of university students. Language service enterprises and relevant practitioners actively participate in the fight against the epidemic, and provide a large number of translation services for online anti-epidemic activities. On average, language service enterprises invested 156,700 yuan in various poverty alleviation funds. In 2019, the global output value of language service industries has approached 50 billion dollars for the first time; in China, there are 403,095 in-service enterprises providing language services and 8,928 in-service enterprises with language services as the main business. The total output value is up to 38.4 billion yuan, showing an annual growth of 3.2\%. English, Japanese, German, French and Russian rank the top five languages in translation; information technology, educational training and intellectual property rights dominate the main translation domains in the domestic language service industry (https://www.sohu.com/a/465061174_378467).

Remote language service activities under the support of Internet technology have become the new normal. Most of language service researches focus on the academic frontier, but the practical problems of the industry draw little attention.

In language service companies, there are many kinds of positions related to translation and localization. Apart from traditional interpreters and translators, there are also Project Manager, Linguist, DTP Specialist, Technical Writer, voice-over and lip-syncing talents, Creative Translator and so on. The development of the language service requires translation talents to be equipped with some new abilities besides the language knowledge.

\subsection{New Demands for Translation Teaching}

The translation teaching mode should be improved in line with the requirements of the market and the translation service suppliers' ability demand. According to the European language service industry certification standard Translation Services-Requirements for Translation Services (ISO 17100 2015: 6), translators should be equipped with at least six professional abilities, namely: 1) translation competence: including the ability to address the problems of language content comprehension and language content production and the ability to render the target language content in accordance with the client-TSP agreement and other project specifications; 2) linguistic and textual competence in the source language and the target language: understand the ST, fluency in the TT, and general or specialized knowledge of text-type conventions; 3) competence in research, information acquisition, and processing: the ability to efficiently acquire the additional linguistic and specialized knowledge necessary to understand the ST and to reproduce the TT; 4) cultural competence: ability to make use of information on the behavioural standards, up-to-date terminology, value 
systems, and locale that characterize both source and target language cultures; 5) technical competence: knowledge, abilities, and skills required to perform the technical tasks in the translation process; and 6) domain competence: using the appropriate style and meaning.

With the development of society, the tasks and activities undertaken by translators become more abundant and diversified. The change of translation profession naturally affects the requirements for translators. In accordance with the survey on the translation talents requirement from 35 enterprises, today's translators are expected to have the abilities including bilingual conversion, comprehensive analysis of the project and decision-making, discourse processing (cross-cultural communication), and competence in some professional fields, including project implementation and management, editing and proofreading, and use of modern technical tools. What is no doubt is that the abilities required for a qualified translator is never unchanged, but endowed with new definitions with the passage of the society and industries.

On November 3, 2020, the new liberal arts construction conference was held in Shandong University to take counsel together as to the talents development plan of liberal arts education in the new era, releasing the Declaration on the construction of new liberal arts, and putting forward the comprehensive improvement of new liberal arts construction. The educational concept of "new liberal arts" was firstly proposed by Hiram college, which has comprehensively revised the training curriculum, reorganized 29 majors, integrated new technologies into the subjects such as philosophy, literature, language and other courses, and provided a comprehensive interdisciplinary cultivation subjects for students in October 2017. Wang Mingyu and Zhang Tao (2019, p. 3) believed that "The new liberal arts is a concept in contrast to the traditional liberal arts. It breaks through the thinking mode of the traditional liberal arts against the background of the new scientific and technological revolution, new round of economic development and the new era of socialism with Chinese characteristics, and pursues for innovation based on inheritance, intersection and integration of several disciplines, collaboration and sharing acting as the main way to promote the interdisciplinary and deep integration, and promote the renewal and upgrading of the traditional liberal arts. As an inalienable part of it, translation teaching mode should also observe the industry performance, changing from major-oriented to market-oriented, from professional segmentation to cross integration, and from adaptive service to support leading”.

As far as the background of new liberal arts is concerned, the critical role of information technology as a tool to more creative and dynamic English teaching is becoming more prominent, Chinese-English interactive translation teaching is typically included. Specifically speaking, the informatization and intellectualization of translation education are mainly manifested in the following two aspects: firstly, informatization and intellectualization have emerged into the environment of translation teaching and learning, which has changed the traditional teaching mode; Secondly, with the development of network media and we-media, as well as the upgrading of data transmission, network resources have increasingly provide a new and convenient learning means for students. Similar to textbooks and teaching aids, the media can also be diversified, including text, video, radio and so on. It can be said that the development of artificial intelligence technology and its increasingly widespread use in learning are gradually leading to disruptive changes in concepts and modes of translation teaching.

As early as 2010, Chen Jianlin (2010) pointed out that computer network and information technology are no longer auxiliary tools for foreign language teaching, but have become a necessary component integrated into foreign language curriculum. Hu Jiasheng and Chen Jianlin (2013) believe that this has promoted a new discipline of foreign language teaching research, namely foreign language educational technology. Based on a large-scale social survey, EDUCAUSE has published Horizon Report for 19 consecutive years, focusing on the impact of information technology on all levels of education. In 2020, it reports six emerging technologies and practices that will have a significant impact on the future of higher education, namely adaptive learning technologies, AI/machine learning education applications, analytics for student success, elevation of instructional design, learning engineering and UX design, open educational resources, and XR (AR, VR, MR, Haptic) technologies (horizon report, 2020).

From the above analysis, it can be seen that changes in the requirements for translation talents and development of technologies give rise to the transformation and upgrading of the translation teaching mode.

\section{Analysis on the Status of Translation Teaching Mode}

\subsection{Improved recognition of Industry-University Cooperation}

Against the backdrop of the gradual professionalization of translation, the industry standard and relevant teaching system have not completely formed. In order to better cope with the new social changes and adapt to the new requirements of the industry, the cooperation between industry and university gained more and more recognition. The means of industry-university cooperation is an inevitable option for the development of language service industries and relevant 
industries in the future. It is necessary to strengthen the communication and cooperation between enterprises and universities, so that the translation quality can reach a higher level in both macro and micro respects. Industry-university cooperation has been put forward in China for a period of time, and now scholars from all walks of life, different majors and research directions have given their own understanding and definition of industry-university cooperation, and applied it to their own discipline development and construction.

Since the 21st century, experts and scholars in various related fields have made their own analysis and judgment on the development of their own disciplines and the combination of social, political, economic, cultural and ecological aspects based on their own disciplinary background and social trends. These disciplines cover a wide range, mainly concentrated on the following categories (see Graph 1). It can be found out that the researches on industry-university cooperation are mainly concentrated on vocational education, enterprise economy and economic system reform, which account for $43.16 \%, 22.11 \%, 17.89 \%$ respectively. But the number of researches on foreign languages show a very low proportion (1.05\%), from which topics of how to better integrate language service industries with relevant service suppliers represented by the university is relatively rare.
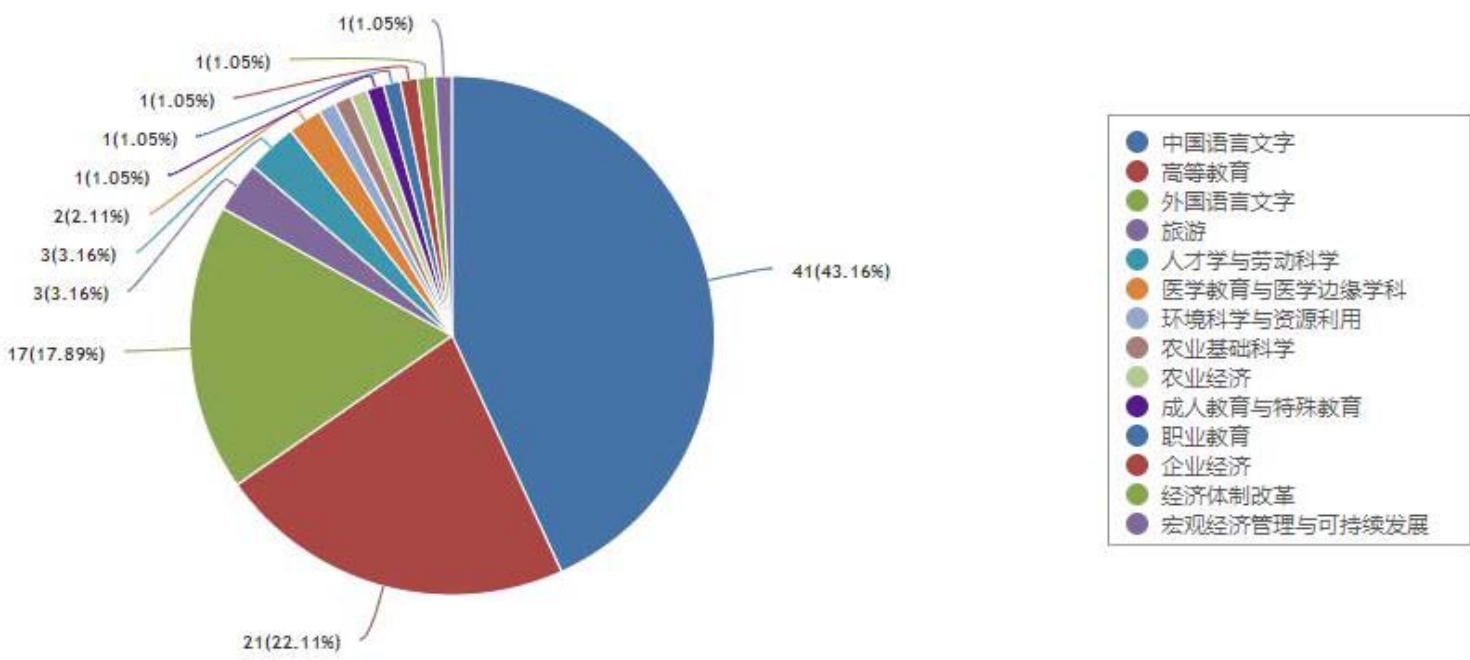

Graph 1. Subject distribution of bibliography relevant to the industry-university cooperation.

Looking through the domestic bibliography, the relevant researches on language service is mainly based on the language service industry development report, which leads to the research lacking of support of practice and deviating from the social needs. Partly due to the low participation of economists entering the language service industry, the current research on language service is relatively shallow and short of guidance for the teaching in the future. Although a few universities, such as Beijing Language and Culture University, Nanjing University and Shandong University, have studied the language ontology from the perspective of economics, they are mainly limited to discussing the basic concepts, the operation rules and industrial layout of the language industry. The research on language service industry is also limited to the industry research column of Chinese Translators Journal and the series of research on language service and language competence published in the Journal of Yunnan Normal University.

On the whole, the research hierarchy of language service is relatively low, the publication edition is relativelylow-grade journals, and few master and doctoral theses focusing on this theme. Most of the research results also focus on perceptual evaluation and analysis, lack of rational value judgment and guidance value for later research.

In accordance with the search condition: ((subject\% = 'Chan Xue (industry-university)'or Title\% = 'Chan Xue (industry-university)'or title= xls ('Chan Xue (industry-university)') or V_Subject = xls ('Chan Xue (industry-university)')) AND (subject\% = 'Fanyi (translation)' or title \% = 'Fanyi (translation) 'or title = XLS ('Fanyi (translation)') or V_ Subject = xls ('Fanyi (translation)'); Search scope: general database, the total number of literature is up to 71, and the number of papaers revealed a trend of fluctuations in different periods. Despite few published papers around this research, the overall number of published papers has shown an upward trend since the year of 2010. It can be seen that the language service industry has begun to attract more attention even though the line show some downward trend from 2016 to 2018 (see Figure 1). 


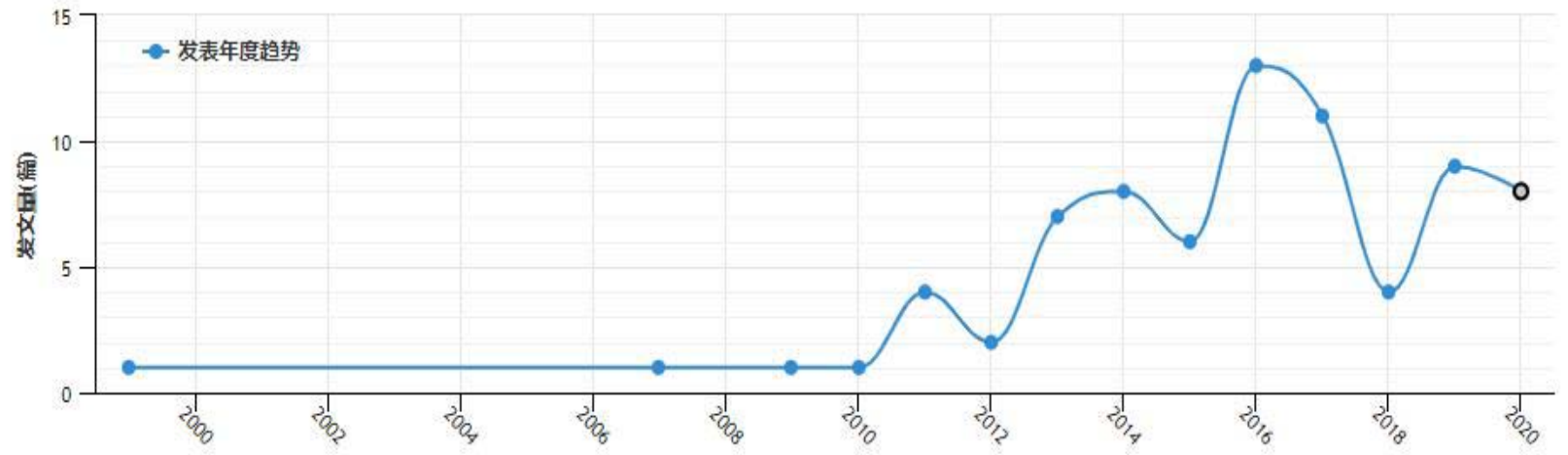

Figure 1. Trend in the number of papers published on language service industry research in recent 20 years.

Similar to the trend of in the number of papers published on language service industry research, the papers around the translation teaching also show an upward trend during the year from 2011 to 2017, while after the year of 2017, relevant studies show a downward trend (see Figure 2).

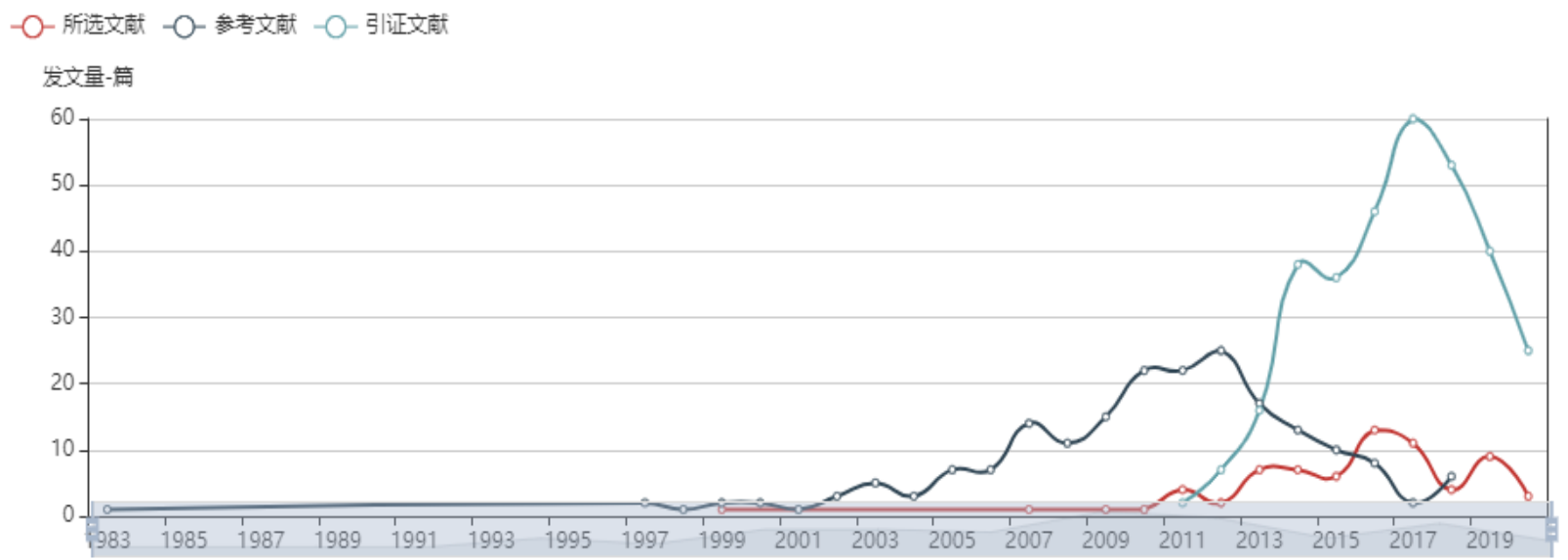

Figure 2. The overall distribution of translation teaching papers under the cooperation of industry-university research.

Beginning from the 21st century, the cooperation mechanism of industry-university has founded and experienced several big ups and downs. The main problem in the adoption of this cooperation lies in that the industry, including many researchers, does not show a high degree of understanding for this cooperation mode. It is only a rough study catering to the national initiatives and trends, and there are many problems in an urgent need of deep thinking, such as unclear definition of the concept and insufficient conclusions.

Since the establishment of translation major in 2006, it had gained solid foundation, while with the development of technology and improvement of language service industries, the traditional translation discipline must seek to find out a new way to solve practical problem existing in the practice. The core of language service is the combination of enterprises and academic institutions, taking into account both theory and application, conducting researches oriented to subject ontology, which requires universities and industries to make preparations and strengthen cooperation.

\subsection{Establishment of online and offline Hybrid Teaching}

Influenced greatly by COVID-19 and renewed education revolution put forward by the government, more and more colleges and universities turned their eyes to the adoption of advanced technologies in the teaching, and introduced online and offline hybrid teaching into the translation pedagogy, which is a good attempt and irreversible teaching trend, even though the result may turn out not as we expected.

At present, the translation course teams in most universities have followed the trend of establishing online courses to improve the efficiency and quality of teaching, and implementing the second round of teaching practice of online and offline hybrid teaching mode against the post-pandemic backdrop. Taking MOOC in Nanjing University as an example, 
the interactive Chinese-English translation course is based on the central teaching platform with a perfect network teaching resource system. All the teaching frameworks, structures, processes, progresses, demonstrations, exercises, assignments, tests, discussions and videos are designed and released independently on the platform.

Combined with the experience from most universities, the online teaching part usually integrates the syllabus, teaching design, teaching process, teaching content, teaching video, translation cases, exercises, discussions \& assignments, teaching expansion, teaching management, as well as relevant links of network resources, etc. The online teaching resource system of English-Chinese translation does not only meets the needs of classroom teaching reform, but also provides rich resources and convenient learning ways for students' self-study, and studies prior to and after the offline classes.

The online teaching video of the course is usually uploaded before the offline teaching, and its function is to assist students to get acquaintance with the knowledge through the means of self-study, discussion and answering, which is a good means of cultivating the independent thinking and group cooperation ability. After seeing the video, students can have a discussion on the questions below the video and get comments from the teacher. In that way, students can have more interactions with the teacher, and on the other hand, the teacher can also figure out the weakness of students in learning to readjust their offline teaching design, teaching focus and teaching progress. In the class, the APP installed on the phone or i-pad could be used to check the presentation of students and ask or answer the student in classroom with the random roll call. After the class, tasks will be assigned online and students can submit online to get the grade point.

Besides above mentioned advantages of this online and offline hybrid teaching method, there are also many weaknesses waited to be improved. Firstly, for the offline teaching part, translation teachers need to provide rich typical translation examples for case teaching at the same time of paying attention to the systematization of knowledge in classroom teaching. Now the original texts used in translation case analysis are usually abstracted from some literal works and translation versions can be searched on the internet. To avoid students to search for target text versions and improve the authenticity of the cases, these original texts can be taken from documents of language service projects in the enterprises that do not involve confidentiality agreement.

Secondly, the type of the translation video can be more abundant. It does not mean the video released should cover content as more as possible, but to have more latest information shown up in the industries, manifesting the features of the course, cultivation of the students' practical capabilities, as well as the orientation of the curriculum and university. Under the guidance of the principle of intensive teaching and expansive practice, more translation training of simulating real scenes shall be accomplished, so that the knowledge of theories and skills learned in the class can be consolidated.

\subsection{Adoption of Modular teaching design}

C-E Interactive translation is a basic curriculum set for translation students to improve their ability of bilingual conversion ability, and translation skills. Through this class students are supposed to acquire basic theories of translation, and strategies, methods as well as skills applied when translating.

The translation teaching mode adopted in most universities including nation-level and province-level is still carried out in line with several different modules. Taking C-E translation set in Shaanxi Normal University as an example, the first module of the course is a brief introduction to translation, which aims to cultivate students' awareness of differences between two languages in terms of syntax and semantics. And the second module is subject choosing and information focus in translation, from which students can learn how to choose a proper subject for target language (subject-prominent) from the source language (topic-prominent). After that, the third module goes on discussing on the predict choosing in accordance with the theme. And in this part two important concepts in modern linguistics, including theme and rheme are introduced to improve students' ability of information judgment and bilingual conversion. The fourth module is cohesion and coherence, training students to use methods like combination, division, and conversion to make the whole context more fluent and cater to the "tree-structure" of the English language. The fifth module focuses on the translation of long sentences such as complex sentences and compound sentences, and makes instructions on how to readjust the word order according to the sentence structure of the source text. The sixth module is the learning of cultural elements in the translation, aiming to cultivating students' awareness of culture and can figure out the deeper connotation behind the superficial meaning.

This module teaching design is widely used in the translation teaching and gained wide-spread acceptation for years, which is systematic on the superficial level; however, it ignores the participation of students to some extent and it's hard for students to grasp the knowledge based on the basic translation skill training. To improve the teaching quality, this traditional modular teaching mode shall be made some improvements in combination with the advanced teaching technology, improved teaching methods and requirements of the language services. 


\section{Construction of Translation Teaching Framework}

\subsection{Building the Industry-University Cooperation Mechanism}

Enterprises are the most important market participant, playing the role of integrating the production factors and stimulating the development motivation. National economic development and innovation ability are mainly reflected in the improvement of independent innovation ability of enterprises. At the same time, enterprises have the first-hand information about the society's demand for technology and talents. Without the demand of enterprises, there will be no need for cooperation among industry and university. From the perspective of schools and scientific research departments, the value of talents and visible achievements of teaching and training ultimately needs to be realized in enterprises, which are the starting point and destination of teaching and scientific research (Hong Yinxing, 2015). After obtaining talents and achievements, enterprises make use of their own equipment, funds and management advantages to carry out industrialization, return part of the income to scientific research, and provide preliminary funds for the development of new products for scientific research, so as to continuously provide guarantee for the deepening of scientific research. At the same time, the enterprise provides the information of talent training experiment, practice base and talent demand for teaching, reduces the cost of talent training, improves the quality of school talent training, and realizes the accurate positioning of school talent training objectives. As the proposer of the actual needs in the society, the provider of important resources and the leader of the implementation of effectiveness evaluation, enterprises are in an increasingly dominant position in the industry-university-research cooperation, while other parties should be engaged in $\mathrm{R}$ \& D and talent training activities around the guidance of enterprises (Hong Yinxing, 2015).

In face of these social needs, the construction of the cooperation mechanism of industry, university and research is in an urgent need of adhering to the concept of mutual benefit and cooperation. According to different needs and problems, universities should establish a developing mechanism in accordance with the changes happened in the society and demands from industries. Specifically speaking, a "professional dynamic developing mechanism based on social needs" should be established in the first step. Focusing on the national and regional development, universities on different levels should dynamically adjust the professional direction, continuously refine the professional characteristics, choose cooperative enterprises, carry out project cooperation, and continuously optimize the practice platform.

Universities should establish and move ahead with the "collaborative education platform development mechanism based on production community". Now a great number of universities have gradually implementing the "dual teacher system", that is to invite experimental experts from the enterprises to teach as visiting professors or carry out relevant technical lectures to convey the latest information in industries and techniques in translation. Many universities have made bold attempt in this respect, such as Xi'an Fanyi University, inviting full-time translators from Beijing Cema Group to explain the translation skills; and Xi'an International Studies University, employing more than 30 industry experts from RWS to participate in course construction and teacher training.

Besides above two points, the training of teachers is also of crucial importance, and a "development mechanism of translation teachers' practical ability” should be established. In recent years, China National Committee for Translation \& Interpreting Education make full use of the advantages of online teaching, highlight the combination of "learning and practice" training mode, and cooperate with many international organizations such as FIT, CIUTI, AIIC, MIIs and the world's top translation universities to provide professional training for the translation teachers. Professional teachers should be encouraged to join the "industry\& learning community" and participate in the school enterprise cooperation project in the whole process to change the development mode of teachers' practical ability from "dependence on outside resources" to "independence on themselves".

In order to reduce the disconnection between the supply and demand of talents and the information asymmetry between the supplier and demander, cooperation between industry, university and research should be further strengthened to create a collaborative education environment. The cooperation mechanism of industry-university-research can fundamentally solve the problem of disconnection between education in the "ivory tower" and requirements in the industries, narrow the gap between university language service talent training and corporate needs, and enhance the social adaptability and competitiveness of graduate students. Establishing a cooperative entity of industry-university-research and turning the enterprise into a "second classroom" is one of the ways to effectively implement the cooperation among industry-university-research. In the formulation of talent training programs and teaching practices, enterprises plays an important role as a bridge between the university and the society for translation students, establish a real industry-university-research cooperation entity, provide students with language service practices, and make enterprises a "second classroom" for students to learn.

The integration and optimization of multiple innovative elements will help to break the time and space constraints of the traditional translation education environment and the barriers between universities and enterprises, realize the ra- 
tional allocation and efficient sharing of intellectual resources, technical resources and task resources, and achieve the comprehensive effect of inclusiveness and win-win cooperation between talent training and industrial development.

\subsection{Improving the Curriculum System}

From the surveys got from the industries and analysis made above, it can be easily found out that a successful translation curriculum design has some particular features, including: making adjustments in line with the dynamic market demands; combing the theory and practice, more importantly, putting the theories into practice; paying attention to the educational technology and technological education, focusing on the cultivation of culture and the interdisciplinary ability; and emphasizing the authenticity of translation environment and programs.

Professor Zhong Weihe noted that the construction of curriculum system for foreign language majors under the background of national standards should deal with four pairs of relationships, namely, general education and professional education; language skills training and professional knowledge teaching; compulsory courses and elective courses; course teaching and practice training (Zhong Weihe, 2019). According to the principle of social system theory, curriculum implementation, as a social educational behavior, is in the role of various elements of the social system, and interacts with external system factors and subsystems (Jiang Qiuxia, 2014, p. 41).

The curriculum system design for translation majors should also take the four relationships and the essence of translation into consideration:

Firstly, balancing the relationship between the theory and practice. As above mentioned, the translation courses in most universities still adopt the modular teaching method and are lack of real-scenery practices, which directly leading to the low efficiency in the learning process. Considering that, school-enterprise joint development practice module should be included in the curriculum modules. According to the needs of economic and social development, various genres of translation texts such as patent, contract can be used as original text and divided into different modules. That is to say, the set of modules can be done in line with the genres of the source text rather than the translation skill such as combination, division, and conversion, etc. Under the guidance of the theories such as communicative translation and semantic translation applied for different genres of texts, the translation course can build characteristic curriculum modules to strengthen translation practice referring to different spheres and to improve students' quick reaction and practical ability in translation operation.

Besides that, the online and offline hybrid teaching shall be implemented and improved furthermore, realizing the "Internet plus" course management against the backdrop of new literal arts. The characteristic course should be designed based on the characteristics of the university and the three basic principles applied in translation teaching-“authenticity", "needs analysis" and "student-centered”. First of all, the authenticity of teaching is reflected both in the offline teaching and online teaching, teaching contents and materials. In the guidance of this principle, teachers do not stick to a certain textbook anymore, but turn to current materials in real language service industries to ensure the achievement of teaching objectives. It is the embodiment of authenticity to choose the patent documentary as the teaching material in Xi'an Foreign Studies University. Secondly, teachers should make analysis on both the students' demand and social demand, and the latter one is more important. At present, the social demand for employees in the language service industry is increasingly diversified, which has long gone beyond the traditional interpretation and translation. Curriculum teaching cannot be limited to monotonous translation skills training, but combined with case teaching, pre-service simulation training and other forms to increase the penetration of professional translation knowledge. Besides that, to carry out student-centered teaching, the role and orientation of teachers and students in the classroom should be re-assessed. The classroom is in urgent need of transforming from teacher-centered to student-centered against the backdrop of the emergence of new educational technologies and development of language services.

In conclusion, the construction of the curriculum system for translation majors shall be based on the projects and tasks, combine the social needs and improve the modular teaching design, focus on the cultivation of practical abilities besides the learning of translation skills, and finally realize a "fusion of educational environment, task environment and social environment”.

\subsection{Implementing Project-based Teaching Method}

In the process of cooperation between universities and industries, one of the biggest obstacles lies in that many enterprises show no satisfaction to the students' translation works, which leads to many enterprises reluctant to hand over some projects to student translators and interpreters out of the consideration of the quality of the works and expenses of training. In the face of this dilemma, universities have more works to do to train students relying on the feedbacks from the enterprises, so that students can gradually have higher bilingual conversion ability, translation technique knowledge, and relevant cultural background knowledge. Based on the project, translation learners complete real projects under the 
guidance of professional translators, so as to acquire translation skills quickly and efficiently (Kiraly, 2000, p. 43).

In addition, the rapid development of educational technology is also a gospel for the traditional teaching mode. Tan Yesheng (2017, p. 102) believes that colleges and universities should develop innovative teaching models of translation course based on Internet and information technology, and make full use of new technologies to develop new teaching methods, such as virtual online practice and mobile teaching.

As for the choice of projects, Xi' an international studies universities can be taken as a good example. In the process of selecting the industry-university cooperation practice base project, this university takes authenticity, stability, enlightenment, value and space-time extension as the standard, and forms a project practice mode characterized by "experience, feedback, reflection and construction” through the real and professional work process.

As concerned as the students, through the real translation project of the internship base, they can be more familiar with the explicit and implicit paradigms of translation practice, integrate theory and practice well, and gain improvement in the practical translation experience. The graduate students participating in the project practice can write translation practical reports and papers on this basis, and form the research results that are significant to the translation practice.

As for teachers, the project-based translation practice mode for international language service and the refined operation of the project strongly support the teaching reform of translation practice education base, and they can get more inspiration in terms of the translation teaching mode. In a word, the social value of the real translation project practice in the base has gone beyond the campus itself, extended to different industrial sectors of society, and even government agencies, and become a bridge connecting universities, government and industry.

The practical project-based translation teaching method absorbs and synthesizes the essence of other existing teaching methods, and guides students to understand, internalize, summarize, improve, and gradually contact with reality and develop the comprehensive ability of translation through the confirmation, design and implementation of projects. Project entering into the classroom is one of the practical ways, and the key to this practical teaching mode is to choose the appropriate task and operate it step by step in strict accordance with the professional translation procedure. Its outstanding feature is authenticity.

Take the patent translation case and practice as an example, the course is a project driven translation course developed by the university and enterprises like RWS group. Taking Xi'an Fanyi University as an example, relying on the "163 pan”, students can get practice, feedback, and growth step by step. "163 plan” refers to one mouths' online training (“1”); six mouths' systematic training (“6”); and three years' translation practice in the industries (“3”). Under the "Internet plus" environment, the program can be firstly incubated under the offline projects to help students understand the stylistics of patent documents, and master the basic translation norms and market demand, and these preparatory courses aim to cultivate students' translation skills and the bilingual conversion ability. Then the project simulation and online operation (Cao Huaijun, He Ying, \& Li Ruilin, 2017, pp. 46-51) can be introduced to cultivate students' ability to engage in patent translation practice, and lay a solid foundation for their rapid entry into relevant domestic and foreign enterprises and institutions to engage in intermediate and advanced patent translation work after graduation. The students are divided into several translation groups to try to translate the real patent translation cases. Through comparative study, they can master the norms, strategies, methods and skills of patent translation, supplemented by group mutual evaluation and discussion, and teacher evaluation feedback, so that the students can constantly internalize the knowledge system of patent translation and consolidate the basic skills. It lays a good foundation for the real project simulation. In the real project simulation stage, students accept the real translation task from RWS group, produce the manuscript within the specified time, and submit it to the instructor for review after completion, and then feedbacks return to the translators to reflect and improve.

In the incubation stage, full-time translators of Intellectual Property Publishing House teach lessons online, guiding students to understand the stylistic characteristics of patent documents, and master the basic translation norms and market demand. The next stage is the simulation case translation stage. The students are divided into several translation groups to try to translate the real patent translation cases used in the past. Through comparative study, they can master the norms, strategies and methods of patent translation. Supplemented by group mutual evaluation and discussion, and evaluation feedback, students can constantly internalize the knowledge system of patent translation and consolidate the basic skills. It lays a good foundation for the real project simulation. And in the last step, the translator receives the manuscript through professional website, uses translation technology tools such as Trados, works with professional translators to finish the translation of the source text, and reviews the feedback after submitting.

The project-based translation teaching reflects the real working process and environment of contemporary large-scale language service enterprises, which is missed in the traditional translation teaching in Colleges and universities. The following is the feedback for a student from March to May in this year: 


\begin{tabular}{|c|c|c|c|c|c|c|c|}
\hline 日期 & file name & 语言 & 转组情汤 & $\begin{array}{l}\text { Total } \\
\text { Words }\end{array}$ & tra & 总分 & QA Resu \\
\hline $3 / 28$ & pctcn2019119857-ftewos-000001-en-zh.xml & CN-EN & 由子 & 903 & & 13.53 & Fail \\
\hline $3 / 28$ & pctcn2019120673-ftewos-000001-en-zh.xml & CN-EN & 由子 & 902 & & 2.22 & Pass \\
\hline $3 / 28$ & pctcn2019129276-ftewos-000001-en-zh.xml & CN-EN & 由子 & 833 & & 8.40 & Fail \\
\hline $3 / 28$ & pctcn2019081603-ftewos-000001-en-zh.xml & CN-EN & 由子 & 404 & & 14.81 & Fail \\
\hline $3 / 28$ & pctcn2019082875-ftewos-000001-en-zh.xml & CN-EN & 由子 & 820 & & 3.69 & Pass \\
\hline $3 / 28$ & pctcn2019110669-ftewos-000001-en-zh.xml & CN-EN & 由子 & 495 & & 14.20 & Fail \\
\hline $3 / 28$ & pctcn2019110941-ftewos-000001-en-zh.xml & CN-EN & 由子 & 896 & & 12.26 & Fail \\
\hline $3 / 28$ & pctcn2019111001-ftewos-000001-en-zh.xml & CN-EN & 由子 & 232 & & 0.00 & Pass \\
\hline $3 / 28$ & pctcn2019121051-ftewos-000001-en-zh.xml & CN-EN & 由子 & 485 & & 4.12 & Pass \\
\hline $3 / 28$ & pctcn2019126018-ftewos-000001-en-zh.xml & CN-EN & 由子 & 906 & . & 12.13 & Fail \\
\hline $\begin{array}{l}3 / 28 \\
5 / 2 /\end{array}$ & $\begin{array}{l}\text { octen201912.8842-ftewos-0000001-en-7h.xml } \\
\text { petcri2019101161 ftewos } 000001 \text { en zh.xul }\end{array}$ & $\left.\mid C N-E_{N}\right)$ & $\begin{array}{l}\text { 由于 } \\
\text { 由毛子 }\end{array}$ & $\begin{array}{c}943 \\
931 \\
\end{array}$ & $1 \frac{1}{1,1}$ & $\begin{array}{l}5.39 \\
2.16 \\
\end{array}$ & $\begin{array}{l}\text { Pass } \\
\text { Palss } \\
\end{array}$ \\
\hline $5 / 27$ & peten2019096646-ftcwos-000001-cn-zh.xml & CN-EN & 电子 & 977 & $\therefore$ & 3.06 & Pass \\
\hline $5 / 2 /$ & petcin2019081281 ftewos 000001 en zh.xul & $(C N \mathrm{EN}$ & 电一子 & 861 & $\therefore$ & 3.51 & Pass \\
\hline $5 / 27$ & peten2019087814-ftewos-000001-en-zh.xml & CN-EN & 电子 & 846 & 1. & 3.57 & Pass \\
\hline $5 / 2 /$ & petcin2019104921 ftewos 000001 en zh.xwl & $(: N \mathrm{EN}$ & 机械 & 128 & $\therefore$ & 5.19 & Pass \\
\hline $5 / 27$ & peten 2019074675 -ftewos-000001-en-zh.xml & CN-EN & 电子 & 1218 & & 4.10 & Pass \\
\hline $5 / 27$ & petcin2019071721 ftewos 000001 en zh.xul & $C \mathrm{~N}$ EN & 电一 & 910 & & 0.00 & Pass \\
\hline $5 / 27$ & peten 2019074885 -ftewos-000001-en-zh.xml & CN-EN & 电子 & 1022 & & 5.99 & Pass \\
\hline $5 / 27$ & peten2019074978-ftewos-000001-en-zh.xml & $-\mathrm{E}, \mathrm{N}$ & 电一 & 1034 & & 2.84 & Pass \\
\hline $5 / 27$ & peten 2019074989 -ftewos-000001-en-zh.xml & CN-EN & 电子 & 742 & & 5.35 & Pass \\
\hline $5 / 2.7$ & peren2019074995-ftewos-000001-en-zh.xml & CN-FN & 电一 & 962 & $; \cdots$ & 3.12 & Pass \\
\hline $5 / 27$ & peten2019075049-ftewos-000001-en-zh.xml & CN-CN & 电子 & 621 & & 1.61 & Pass \\
\hline $5 / 2.7$ & percn2019075080-ftewos-000001-en-zh.xml & CN-FN & 电一 & 759 & & 9.2.1 & Fail \\
\hline $5 / 27$ & pctcn20190780b3-ftewos-000001-en-zh.xml & CN-EN & 电一 & 1020 & $\therefore$, the & 2.95 & ass \\
\hline $5 / 2.7$ & peten2019078055-ftewos-000001-en-z.h.xml & CN-FN & 电一 & 1074 & & 5.59 & Pass \\
\hline
\end{tabular}

Figure 3. Example of Students’ Translation Quality Feedback from RWS.

It can be seen that the student's error rate shows an fast reduction, and the pass rate increases remarkably and gradually. From the repeated practice and revision, students became a more independent and mature translator after involvement in translation project just less than two months (see Figure 3).

\subsection{Reconstructing Curriculum Assessment System}

Based on the technical support, theoretical and cultural perspective, the integrated translation curriculum system should integrate the assessments in terms of the content, the process, and the final grade (He Ying \& Li Ruilin, 2015, p. 57).

The assessment for talent training plan and curriculum of “integration of industry, university and research" should share some differences from the traditional teaching mode. The teaching content and teaching mode have been reformed, and the teaching evaluation system should also be readjusted accordingly. Only by combining formative evaluation, process evaluation and summative evaluation can teachers' teaching quality and students' learning effect be truly tested. Therefore, how to carry out the examination reform and improve the standardization and fairness of the examination is worth all teachers' constant thinking.

As mentioned above, the assessment of the translation teaching in most universities nowadays has not just restricted to the performance in the final examination, but also considering the completion of teaching videos and assignments online, discussion participation, and some other translation competitions and tasks. The following is a screenshot of the assessment standard of translation students’ performance in Xi'an Fanyi University: 


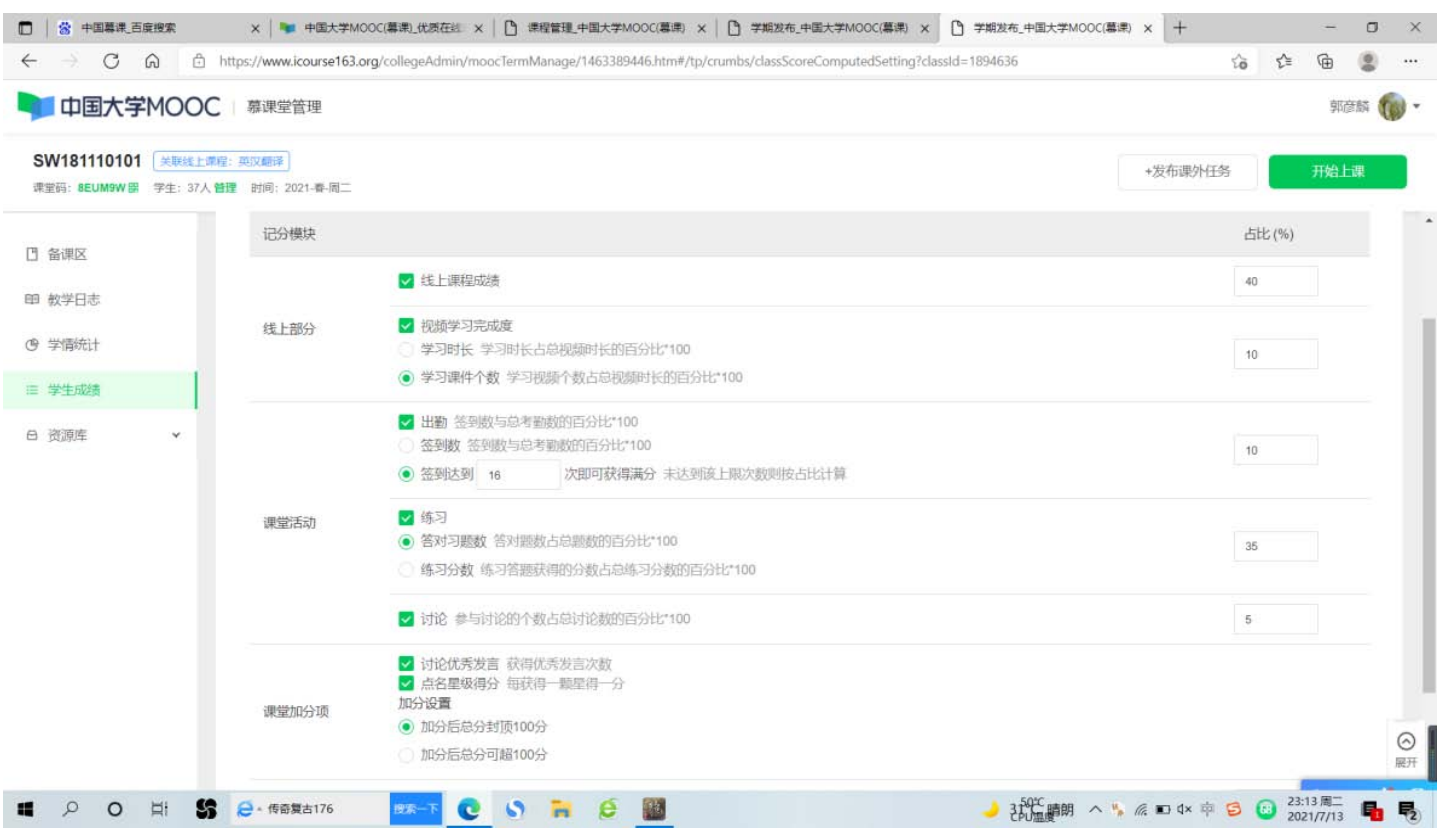

Graph 2. Assessment of translation competence based on offline and online performance.

Above screenshot shows the assessment standard for students on the MOOC, and it can be seen that the online learning accounts for $40 \%$ and video learning completion accounts for $10 \%$. And the activities involvement in the class, including the presence of students, practice and discussion, accounts for 10\%, 35\% and 5\% respectively (see Graph 2).

But it can be clearly seen that the grade of students only depend on the performance in the class (online or offline) and completion of discussion, videos and some online assignments on MOOC platform without considering the actual practice in the industry, which reduces the motivation in participation in the translation projects in language services to some extent. Considering that, the assessment system should include the performance in the industries, realizing the true combination between the industry and the university.

\section{Conclusion}

Based on the market orientation, the study analyzes the current situation of the language service industry and the new requirements for translation teaching against the background of the development of science and technology, as well as the emergence of new liberal arts. The paper summarizes the advantages and weaknesses in existing curriculum design and typical teaching method. In view of the traditional translation teaching mode, the paper elaborates the improvement on translation teaching mode from four aspects: industry-university cooperation mechanism, curriculum system construction, project-based translation teaching method and curriculum evaluation system.

The transformation and upgrading of translation is inevitable, and the rapid development of language service industry requires that translation teaching can no longer ignore the economic value and guiding role of enterprises. Only by putting the enterprise and market demand in the first place of translation teaching design, can we achieve the goal of cultivating "high qualified, and applied” language service talents.

\section{References}

Cao, Huaijun, He Ying, Li Ruilin. (2017). “Project-Driven Training Mode for Patent Translators in the Era of Internet Plus”. Shanghai Journal of Translators, 2017(1): 46-51.

Chen Jianlin. (2010). "Integration of Computer Network and Foreign Language Curriculum—A Study Based on College English Teaching Reform”. Shang Hai: Shanghai Foreign Language Education Press.

China Academy of Translation; Institute of China Translation Development. (2014). "Report on China' s Translation Industry”.

Durban, C., Msatine, T., Mossop, B., Schwartz, R., Searls-Ridge, Courtney. (2003). "Translator Training \& the Real World: Concrete Suggestions for Bridging the Gap”. Translation Journal, 7(1): 1-35.

He Ying and Li Ruilin. (2015). "Research on the Design of Hypothesis Model of Integrated Translation Course”. Chinese Translators Journal, 2015(3): 53-58. 
Hong Yinxing. (2015). “Research on Collaborative Innovation of Industry University Research Institute”. People’s Publishing House.

https://insights.csa-research.com/reportaction/305013292/Marketing.

https://www.educause.edu/horizon-report-2020.

https://www.sohu.com/a/465061174_378467.

https://www.sohu.com/a/465061174_378467.

Hu Jiasheng and Chen Jianlin. (2013). “An outline of Foreign Language Educational Technology”. Technology Enhanced Foreign Language Education, 2013(2): 3-12.

ISO 17100. (2015). “Translation Services-Requirements for Translation Services”. London: The British Standards Institution.

Jiang, Qiuxia. (2014). “On the Implementation of T\&I Curriculum in China”. Chinese Translators Journal, 2014(6): 39-43.

Kiraly, D. (2000). A Social Constructivist Approach to Translator Education: Empowerment from Theory to Practice. St. Jerome.

Mu Lei, Shen Huizhi, and Zou Bin. (2017). "Research on the Ability Characteristics of Translation Talents for International Language Service Industry-Based on the Investigation and Analysis of the top 100 Global Language Service Providers”. Shanghai Journal of Translators, 2017(1).

Tan Yesheng. (2017). "Exploration of Characteristic Translation Education in the New Era: Theory, Mode and Problems-The Second High Level Forum on Translation Studies in Foreign Languages and the National Symposium on Exploration of Characteristic Translation Education”. Journal of Foreign Languages, 2017(3).

Wang Minyu and Zhang Tao. (2019). "On the Construction of New Liberal Arts in Universities_-On the Discipline Construction of Foreign Language and Literature”. Journal of Tianjin Foreign Studies University, 2019(6): 1-7.

Yao Yazhi and Si Xianzhu. (2018). “Talent Demand Analysis of Language Service Industry Based on Big Data”. Chinese Translators Journal, 2018(3).

Zhong, Weihe. (2019). "Translation Education in China in the 40 years of Reform and Opening-up: Achievements, Challenges and Development”. Chinese Translators Journal, 2019(1): 68-75. 